\title{
Biodiversity of 52 chicken populations assessed by microsatellite typing of DNA pools
}

\author{
Jossi Hillel ${ }^{\mathrm{a} *}$, Martien A.M. Groenen ${ }^{\mathrm{b}}$, \\ Michèle Tixier-Boichard ${ }^{c}$, Abraham B. KOrol $^{d}$, Lior DAvid ${ }^{a}$, \\ Valery M. Kirzhner ${ }^{\mathrm{d}}$, Terry Burke ${ }^{\mathrm{e}}$, Asili BARRe-Dirie ${ }^{\mathrm{f}}$, \\ Richard P.M.A. Crooijmans ${ }^{\mathrm{b}}$, Kari Elo ${ }^{\mathrm{g}}$, Marcus W. Feldman ${ }^{\mathrm{h}}$, \\ Paul J. Freidlin ${ }^{\mathrm{a}}$, Asko MäKI-TANILA ${ }^{\mathrm{g}}$, Marian OorTwisn ${ }^{\mathrm{b}}$, \\ Pippa Thomson ${ }^{\mathrm{e}}$, Alain VIGnAL ${ }^{\mathrm{i}}$, Klaus WIMMERs ${ }^{\mathrm{j}}$, \\ Steffen WeIGEND ${ }^{\mathrm{f}}$ \\ a Department of Genetics, The Hebrew University of Jerusalem, \\ Faculty of Agriculture, Food and Environmental quality sciences, \\ Rehovot 76100, Israel \\ b Institute of Animal Sciences, Wageningen Agricultural University, \\ Wageningen, The Netherlands \\ ${ }^{c}$ Institut national de la recherche agronomique, Centre de Jouy-en-Josas, France \\ ${ }^{d}$ Institute of Evolution, University of Haifa, Israel \\ e Department of Animal and Plant Sciences, Sheffield University, S10 2TN, UK \\ ${ }^{\mathrm{f}}$ Institute for Animal Science, Federal Agricultural Research Centre, \\ Mariensee, 31535 Neustadt, Germany \\ g Agricultural Research Centre, Institute of Animal Production, \\ 31600 Jokioinen, Finland \\ ${ }^{\mathrm{h}}$ Department of Biological Sciences, Stanford University, \\ Stanford, CA 94305, USA \\ ${ }^{\mathrm{i}}$ Institut national de la recherche agronomique, Centre de Toulouse, France \\ ${ }^{\mathrm{j}}$ Institute of Animal Breeding Science, \\ Rheinische Friedrich-Wilhelms-Universitat Bonn, Germany
}

(Received 2 September 2002; accepted 13 March 2003)

\footnotetext{
* Correspondence and reprints
} E-mail: Hillel@agri.huji.ac.il 


\begin{abstract}
In a project on the biodiversity of chickens funded by the European Commission (EC), eight laboratories collaborated to assess the genetic variation within and between 52 populations from a wide range of chicken types. Twenty-two di-nucleotide microsatellite markers were used to genotype DNA pools of 50 birds from each population. The polymorphism measures for the average, the least polymorphic population (inbred $\mathrm{C}$ line) and the most polymorphic population (Gallus gallus spadiceus) were, respectively, as follows: number of alleles per locus, per population: 3.5, 1.3 and 5.2; average gene diversity across markers: 0.47, 0.05 and 0.64 ; and proportion of polymorphic markers: $0.91,0.25$ and 1.0. These were in good agreement with the breeding history of the populations. For instance, unselected populations were found to be more polymorphic than selected breeds such as layers. Thus DNA pools are effective in the preliminary assessment of genetic variation of populations and markers. Mean genetic distance indicates the extent to which a given population shares its genetic diversity with that of the whole tested gene pool and is a useful criterion for conservation of diversity. The distribution of populationspecific (private) alleles and the amount of genetic variation shared among populations supports the hypothesis that the red jungle fowl is the main progenitor of the domesticated chicken.
\end{abstract}

genetic distance / polymorphism / red jungle fowl / DNA markers / domesticated chicken

\title{
1. INTRODUCTION
}

It is widely accepted that all populations of domesticated chickens descend from a single ancestor, the Red Jungle Fowl (RJF) (Gallus gallus), originating in Southeast Asia. Although it has been claimed that other wild species of Gallus might have contributed to the domesticated chicken [5], the more widely accepted view is that Gallus gallus gallus alone is sufficient to account for the maternal ancestry of the domesticated chicken $[14,15]$. At the present time, the improved Mediterranean type populations are the most closely related to the RJF, which were the first chickens brought into Europe [33]. Much later, with the massive use of selection and crossbreeding, local breeds and lines in different parts of Europe were developed, and Asian breeds of the Chinese and Malay types were introduced. All of these sources contributed to the modern biodiversity of chicken populations. Inter-crossing, however, may have partly extinguished differences among groups or breeds, with the result that genetic relationships between chicken populations are not always definitive. Furthermore, only some of these sources were used to develop the populations which currently dominate the world's poultry industry [6,27]. Since the start of commercial poultry breeding in the middle of the 20th century, chicken genetic diversity has become partitioned among relatively few highly specialized lines. As a consequence, many dual-purpose breeds, resulting from centuries of domestication and breeding, are now at the risk of being lost. These breeds may, however, represent a resource of genes for future breeding and research purposes. Therefore, it is necessary to assess the diversity at the molecular level in a wide range of chicken populations, including commercial lines, traditional breeds, experimental lines and the red jungle fowl, in order to provide recommendations regarding future management or conservation of 
these populations. Although decisions on conservation of genetic resource populations should rely upon several sources of information, including specific traits of interest, molecular markers may serve as an important initial guide [1]. In the process of developing strategies to conserve genetic diversity in domestic chickens, it is important to assess quantitatively the genetic uniqueness of a given population [43], which may be deduced from genetic distances.

Recent advances in molecular technology have provided new opportunities to assess genetic variability at the DNA level. Currently, microsatellites are widely used since they are numerous, randomly distributed in the genome, highly polymorphic, and show co-dominant inheritance [20,30]. Many microsatellites have recently become available in chickens, and have been mapped in reference populations $[4,8,9,22]$. These markers provide a powerful tool for QTL research, and have also been successfully used to study the genetic relationship between and within chicken populations [36,40,41,45,48]. Reliable information on allele frequencies was obtained from chicken blood or DNA pools using minisatellite markers $[12,13,24,25]$, as well as microsatellites [10,31].

This article reports on the results of the AVIANDIV EC-funded research project $[26,44,47]$. The aim of the study was to evaluate the gene-pool of 52 chicken populations from a wide range of origins. The results may prove to be valuable for the future conservation of genetic resources of chickens.

\section{MATERIAL AND METHODS}

Where possible and relevant, throughout this report, chicken lines, populations, and breeds will be referred to as populations. General information on these populations is presented in Table I and details were reported by TixierBoichard et al. [44]. Information on the markers is given in Table II and a brief description of the populations, markers and genotyping is given below.

\subsection{Populations and animals}

Fifty-two populations were chosen to represent as many European countries as possible and to cover a wide range of populations differing by selection history and current management. We aimed to sample the same number of males and females from as many families as possible, for a total of 50 chickens per population. Sampled populations were classified a priori into six types (Tab. I). Type 1 includes two subspecies of the Red Jungle Fowl, Gallus gallus gallus and G. g. spadiceus which were recently caught in the wild. Type 2 represents five domesticated but unselected chicken populations with substantial morphological variation. Type 3 represents 23 standardized breeds, where selection has been done, either recently or in the past, on morphological traits according to a phenotypic standard. Type 4 encompasses 13 experimental or commercial, white- or brown-egg layer lines. Type 5 includes eight lines 
Table I. Information on populations.

(continued on the next page)

\begin{tabular}{|c|c|c|c|c|c|c|}
\hline \multicolumn{2}{|l|}{ Population } & \multirow{2}{*}{$\begin{array}{c}\text { Type } \\
*\end{array}$} & \multirow{2}{*}{ Origin } & \multirow{2}{*}{$\underset{* *}{\text { Founder }}$} & \multirow{2}{*}{$\underset{* * *}{\text { Creation }}$} & \multirow[t]{2}{*}{ Size (range) } \\
\hline Name & No. & & & & & \\
\hline Gallus gallus spadiceus & 101 & 1 & Thailand & $\mathrm{b}$ & 1997 & 100 \\
\hline Gallus gallus gallus & 102 & 1 & Thailand & $\mathrm{b}$ & 1997 & 165 \\
\hline Fayoumi & 04 & 3 & Egypt & $\mathrm{b}$ & 1978 & $50-300$ \\
\hline Bedouin & 05 & 2 & Israel & a & 1995 & $30-50$ \\
\hline Westfaeliche Totleger & 06 & 3 & Germany & $\mathrm{b}$ & 1904 & 900 \\
\hline Sundheimer & 07 & 3 & Germany & $\mathrm{c}$ & 1886 & $100-500$ \\
\hline Light Brown Leghorn & 08 & 3 & Germany & $\mathrm{b}$ & 1870 & (large) \\
\hline Owl-bearded (Uilenbaarder) & 09 & 3 & The Netherlands & $\mathrm{a}$ & 1650 & 200 \\
\hline Friesian fowl & 10 & 3 & The Netherlands & $\mathrm{a}$ & (unknown) & 50 \\
\hline Bresse noire & 11 & 4.2 & France & $\mathrm{b}$ & 1995 & $400-2500$ \\
\hline Houdan & 12 & 3 & France & $\mathrm{c}$ & 1994 & $50-200$ \\
\hline Marans & 13 & 3 & France & $\mathrm{c}$ & 1988 & $200-350$ \\
\hline Dorking & 14 & 3 & Great-Britain & $\mathrm{b}$ & 1986 & 85 \\
\hline Cochin & 15 & 3 & China & $\mathrm{b}$ & 1946 & 130 \\
\hline Icelandic landrace & 16 & 2 & Iceland & $\mathrm{a}$ & 900 & $2000-4000$ \\
\hline Finnish Landrace & 17 & 2 & Finland & $\mathrm{c}$ & 1900 & $600-1000$ \\
\hline Old Scand. Ref. Pop. & 18 & 3 & Denmark & $\mathrm{c}$ & 1969 & $200-700$ \\
\hline Jaerhoens & 19 & 3 & Norway & $\mathrm{a}$ & 1916 & $300-400$ \\
\hline Sicilienne Buttercup & 20 & 3 & Italy- Sicilia & b & 1990 & 150 \\
\hline Padovana & 21 & 3 & Italy & $\mathrm{b}$ & 1986 & $35-350$ \\
\hline Black Castellana & 22 & 3 & Spain & $\mathrm{a}$ & 1975 & $200-300$ \\
\hline Red Villafranquina & 23 & 3 & Spain & $\mathrm{a}$ & 1980 & $200-300$ \\
\hline Czech Golden Pencilled & 24 & 3 & Czech Republic & $\mathrm{c}$ & 1995 & $500-1000$ \\
\hline Oravka hen & 25 & 3 & Slovakia & $\mathrm{c}$ & 1994 & $50-100$ \\
\hline Transsylv. Naked Neck & 26 & 3 & Hungary & a & 1990 & $70-220$ \\
\hline Green-legged Partridge & 27 & 3 & Poland & a & 1950 & 1600 \\
\hline Orlov & 28 & 3 & Russia & $\mathrm{c}$ & 1960 & 2000 \\
\hline Yurlov crower, in Russia & 2901 & 3 & Russia & $\mathrm{c}$ & 1976 & 10000 \\
\hline Yurlov crower, in Ukrainia & 2902 & 2 & Ukraine & $\mathrm{b}$ & 1870 & $140-700$ \\
\hline Ukrainian bearded & 30 & 2 & Ukraine & $\mathrm{b}$ & 1850 & 74-105 \\
\hline Poltava clay & 31 & 3 & Ukraine & $\mathrm{b}$ & 1870 & $2000-6000$ \\
\hline $\mathrm{C}$ line & 32 & 6 & Czech Republic & $\mathrm{a}$ & 1932 & $180-600$ \\
\hline Gödöllö Nhx, & 33 & 4.15 & Hungary & $\mathrm{c}$ & 1996 & $600-8000$ \\
\hline Line Sarcoma-Resistant & 3401 & 4.10 & $\begin{array}{l}\text { USA, now in } \\
\text { Germany }\end{array}$ & $\mathrm{b}$ & 1965 & 200 \\
\hline Line Sarcoma-Susceptible & 3402 & 4.10 & $\begin{array}{l}\text { USA, now in } \\
\text { Germany }\end{array}$ & $\mathrm{b}$ & 1965 & 200 \\
\hline White-egg layer A & 37 & 4.3 & commercial & $\mathrm{b}$ & 1959 & 6000 \\
\hline Brown-egg layer A & 38 & 4.4 & commercial & b & 1979 & 5000 \\
\hline Broiler dam line A & 39 & 5.1 & commercial & $\mathrm{c}$ & 1980 & 10000 \\
\hline Broiler sire line A & 40 & 5.2 & commercial & $\mathrm{c}$ & 1980 & 10000 \\
\hline Broiler dam line B & 41 & 5.1 & commercial & $\mathrm{a}$ & 1960 & $5000-30000$ \\
\hline Broiler sire line B & 42 & 5.2 & commercial & $\mathrm{b}$ & 1970 & $10000-70000$ \\
\hline Brown-egg layer B & 43 & 4.4 & commercial & $\mathrm{c}$ & 1960 & 5000 \\
\hline Brown-egg layer line $\mathrm{C}$ & 44 & 4.4 & commercial & $\mathrm{b}$ & 1960 & 5000 \\
\hline Brown-egg layer line D & 45 & 4.4 & commercial & $\mathrm{b}$ & 1962 & 1000 \\
\hline
\end{tabular}


Table I. Continued.

\begin{tabular}{lcclccc}
\hline \multicolumn{1}{c}{ Population } & & $\begin{array}{c}\text { Type } \\
*\end{array}$ & Origin & $\begin{array}{c}\text { Founder } \\
* *\end{array}$ & $\begin{array}{c}\text { Creation } \\
* * *\end{array}$ & Size (range) \\
\cline { 1 - 2 } Name & No. & & & & & \\
\hline Brown-egg layer line E & 46 & 4.4 & commercial & $\mathrm{b}$ & 1955 & 600 \\
Broiler sire line C & 47 & 5.2 & commercial & $\mathrm{a}$ & 1974 & confidentiel \\
Broiler dam line C & 48 & 5.1 & commercial & $\mathrm{a}$ & 1974 & confidentiel \\
Broiler sire line D & 49 & 5.2 & commercial & $\mathrm{a}$ & 1992 & 8000 \\
Broiler dam line D & 50 & 5.1 & commercial & $\mathrm{b}$ & 1970 & $5000-20000$ \\
Ab line, high & 51 & 4.15 & The Netherlands & $\mathrm{c}$ & 1980 & $75-300$ \\
Ab line, low & 52 & 4.15 & The Netherlands & $\mathrm{c}$ & 1980 & $75-300$ \\
Ab line, control & 53 & 4.15 & The Netherlands & $\mathrm{c}$ & 1980 & $110-250$ \\
\hline
\end{tabular}

* type: $1=$ wild population; $2=$ domesticated unselected breed; $3=$ standardized breed selected on morphology; $4=$ Layers, selected on quantitative traits; $5=$ Broilers, selected on quantitative traits; $6=$ inbred line.

Detailed information for type 4: $4.10=$ experimental White Leghorn; $4.15=$ experimental brown egg layer; $4.2=$ commercial white egg layer not White Leghorn; $4.3=$ commercial White Leghorn; $4.4=$ commercial brown-egg layer.

Detailed information for type 5: $5.1=$ commercial broiler dam line; $5.2=$ commercial broiler sire line.

** founder: $\mathrm{a}=$ small flock; $\mathrm{b}=$ one breed; $\mathrm{c}=\mathrm{a}$ cross between several breeds.

*** estimate for the Creation Time of the sampled flocks.

of meat type chickens: four broiler dam-lines and four broiler sire-lines. For lines of types 4 and 5, selection has been applied on a quantitative trait or on an index. Experimental lines included two sets of divergently selected lines. Type 6 is an inbred line.

\subsection{Blood and DNA samples}

Blood samples of 2-4 mL were collected from the wing vein with Sarstedt Syringes containing EDTA as an anti-coagulating agent. In 20 populations, blood samples were collected on the same day and blood cells from individual birds were obtained from fresh blood by centrifugation and were re-suspended in an equal volume of PBS/Sucrose (1v/1v). DNA pools from each population were used to reduce the amount of genotyping. An aliquot of $50 \mu \mathrm{L}$ of blood cells in PBS/Sucrose from each bird in a population was taken to prepare its blood pool. Individual blood samples and blood pools were frozen at $-25^{\circ} \mathrm{C}$. High molecular weight DNA was extracted from $80 \mu \mathrm{L}$ of the blood pool, following several steps of haemolysis, proteinase $\mathrm{K}$ incubation, precipitation in dimethyl-formamide/acetone $(95 \mathrm{v} / 5 \mathrm{v})$, re-suspension in TE, ethanol precipitation and final re-suspension in $2 \mathrm{~mL}$ TE. For the other 32 populations, a blood pool could not be made properly, either because the individual blood samples had been frozen, or because their quality was not good enough. Consequently, DNA was extracted from individual blood samples and the pooled DNA sample 


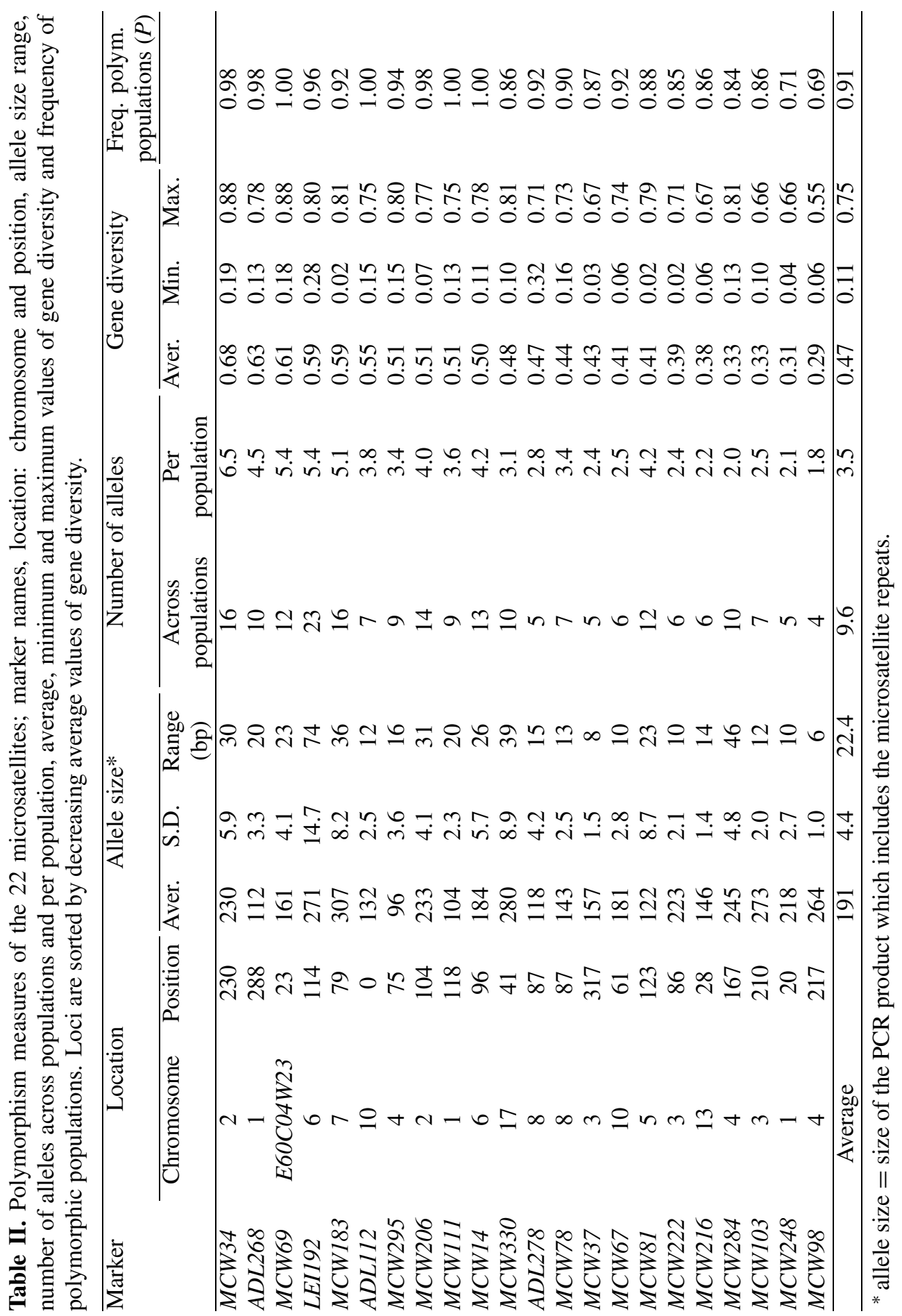


was prepared by aliquoting equal amounts of individual DNA, as measured by spectrophotometry. Prior to genotyping, the concentration of the DNA pools was standardized to $100 \mathrm{ng} \cdot \mu \mathrm{L}^{-1}$ in TE solution. The genotyping of the 52 populations was done for 22 microsatellite loci.

\subsection{Genotyping at microsatellite loci}

A set of 22 (CA)n di-nucleotide microsatellite markers, which are as uniformly distributed as possible throughout the chicken genome, was tested for their use in DNA pools. The markers and their genomic position are listed in Table II. Peak scoring on an ABI sequencer was used to estimate microsatellite allele frequencies as detailed in Crooijmans et al. [10]. PCR products of different markers were pooled in such a way that each marker signal on the ABI sequencers did not exceed a peak height of about 1000 to 1500. Fragment sizes were determined relative to the GENESCAN-350 TAMRA with the GENESCAN fragment analysis software (Perkin Elmer, Applied Biosystems Division). Subsequently GENOTYPER software (Perkin Elmer, Applied Biosystems Division) was used for automated fragment calling and the generation of an output table containing the fragments for the different loci and the peak areas for each of these fragments. Finally, these peak areas were used to calculate the relative fragment frequencies for all peaks of each locus. These frequencies were used in this study as the allele frequencies. However, alleles scored from DNA pools using an ABI sequencer, might be artefacts and stutter bands rather than real alleles. We assumed that this difficulty would be relevant equally to all populations and most markers.

\subsection{Gene diversity estimate}

Using the calculated allele frequencies $P_{m i}$ for population $m$ and allele $i$, gene diversity $\left(H_{m}\right)$, namely the expected heterozygosity under Hardy-Weinberg assumptions, is:

$$
H_{m}=1-\sum_{i} P_{m i}^{2} \text {. }
$$

An average $H$ was calculated for each locus across populations and for each population across loci.

\subsection{Genetic distance estimates}

Three genetic distances based on allele frequencies were used: the Nei genetic distance [34], Cavalli-Sforza chord measure [3] and Reynolds genetic distance [38]. Additionally, the delta-mu-squared distance [18,19], based on allele size, was applied. Pairwise distances between each pair of the 52 populations (1326 estimates) were calculated for each measure. 


\subsection{Statistical analyses}

Correlation coefficients and rank correlations were estimated using JMP 4.0 software [28].

\subsection{Calculation of the mutation rate}

We used the information on the history of the two Sarcoma lines 3401 and 3402 (see Tab. I) and their microsatellites data to estimate the mutation rate of microsatellites in chickens. These lines were divergently selected for resistance or susceptibility to Rous Sarcoma Viruses (RSV) A and B of 2-to-3 wk old chickens [23]. The two sub-lines have been kept separately for 25 generations. The two lines had 74 different alleles of which only 46 (62\%) were shared. At each of the 25 generations, ten sires were selected from each line and mated to approximately 100 dams. In this process, 220 gametes were involved at each generation and for each line, to produce the next generation. We scored the number of microsatellite alleles specific to each of the two lines in comparison to the other one.

\section{RESULTS}

Raw data and basic results such as genetic distances between population pairs of the current study, can be obtained from the Poultry Biodiversity database at: http://w3.tzv.fal.de/aviandiv/index.html.

A total of 3760 allele frequencies were obtained. Amongst the 1144 possible typings ( 22 markers $\times 52$ populations), $77(6.7 \%)$ were missing due to technical difficulties, mainly for three loci: $A D L 278, M C W 14$, and MCW330, with missing data on 27,15 , and 15 populations, respectively. For the remaining 19 markers, only 20 (2.0\%) genotyping data points were missing.

\subsection{Polymorphism of markers}

As shown in Table II, all 22 markers were polymorphic in at least $69 \%$ of the populations, and $91 \%$ of the populations were polymorphic. The mean number of alleles was 9.6 across populations and 3.5 within populations, and average gene diversity was 0.47 . Among the 22 tested markers, the most polymorphic was $M C W 34$ with 16 alleles across populations and, on average, 6.5 alleles per population. The gene diversity of $M C W 34$ was 0.68 and $98 \%$ of the populations were polymorphic for this marker. At the other extreme, marker MCW98 was the least polymorphic, with four alleles across populations, 1.8 alleles per population, and a gene diversity of 0.29 ; in addition it was polymorphic in $69 \%$ of the populations. 
Table III. Correlation coefficients between polymorphism measures of markers and their statistical significance $(p)$.

\begin{tabular}{lccc}
\hline Polymorphism measure & $\begin{array}{c}\text { Alleles across } \\
\text { populations }\end{array}$ & $\begin{array}{c}\text { Alleles per } \\
\text { population }\end{array}$ & $\begin{array}{c}\text { Expected } \\
\text { heterozygosity }\end{array}$ \\
\hline Size difference & 0.87 & 0.51 & 0.41 \\
Alleles across populations & $(0.00001)$ & $(0.01)$ & $($ n.s. $\dagger)$ \\
Alleles per population & & 0.81 & 0.65 \\
& & & $(0.0011)$ \\
${ }^{\dagger}$ n.s. $=$ non significant. & & & 0.91 \\
\end{tabular}

The associations between the various measurements of marker polymorphism are presented in Table III. The number of alleles across the populations was highly correlated with the difference between the smallest and the largest allele at a locus $(r=0.87)$ and as expected, with the number of alleles per population $(r=0.81)$. Gene diversity was highly correlated with the number of alleles per population $(r=0.91)$ but to a lesser extent with the number of alleles across populations $(r=0.65)$. Based on these associations, it turned out that the markers LEII92 and MCW284 had more alleles across populations than expected from their average number of alleles per population and marker $M C W 34$ had less alleles across populations than expected from its average per population.

\subsection{Diversity of populations}

Table IV presents the diversity measures of the 52 populations. Average gene diversity $(H)$ within the 52 populations across all 22 loci was 0.47 and the average number of alleles was 3.5. The least polymorphic population was the inbred " $C$ line", with a gene diversity $(H)$ of 0.05 and 1.3 alleles per locus across all markers. The next to lowest was Padovana, a fancy breed with a narrow base in Northern Italy, with $H=0.17$, and 1.8 alleles. The most polymorphic population was the Gallus gallus spadiceus, with $H=0.64$ and an average of 5.2 alleles, followed by the population of Yurlov Crower in Russia, with $H=0.62$ and 4.8 alleles.

Within these extreme populations, there was variation across marker loci. In the inbred $\mathrm{C}$ line, the polymorphism ranged from $H=0.39$ and two alleles for marker $A D L 268$ to $H=0$ at 15 of the remaining loci. Similarly, in Gallus gallus spadiceus, polymorphism varied between $H=0.88$ and 11 alleles (MCW69), to $H=0.20$ and 2 alleles (MCW222). 


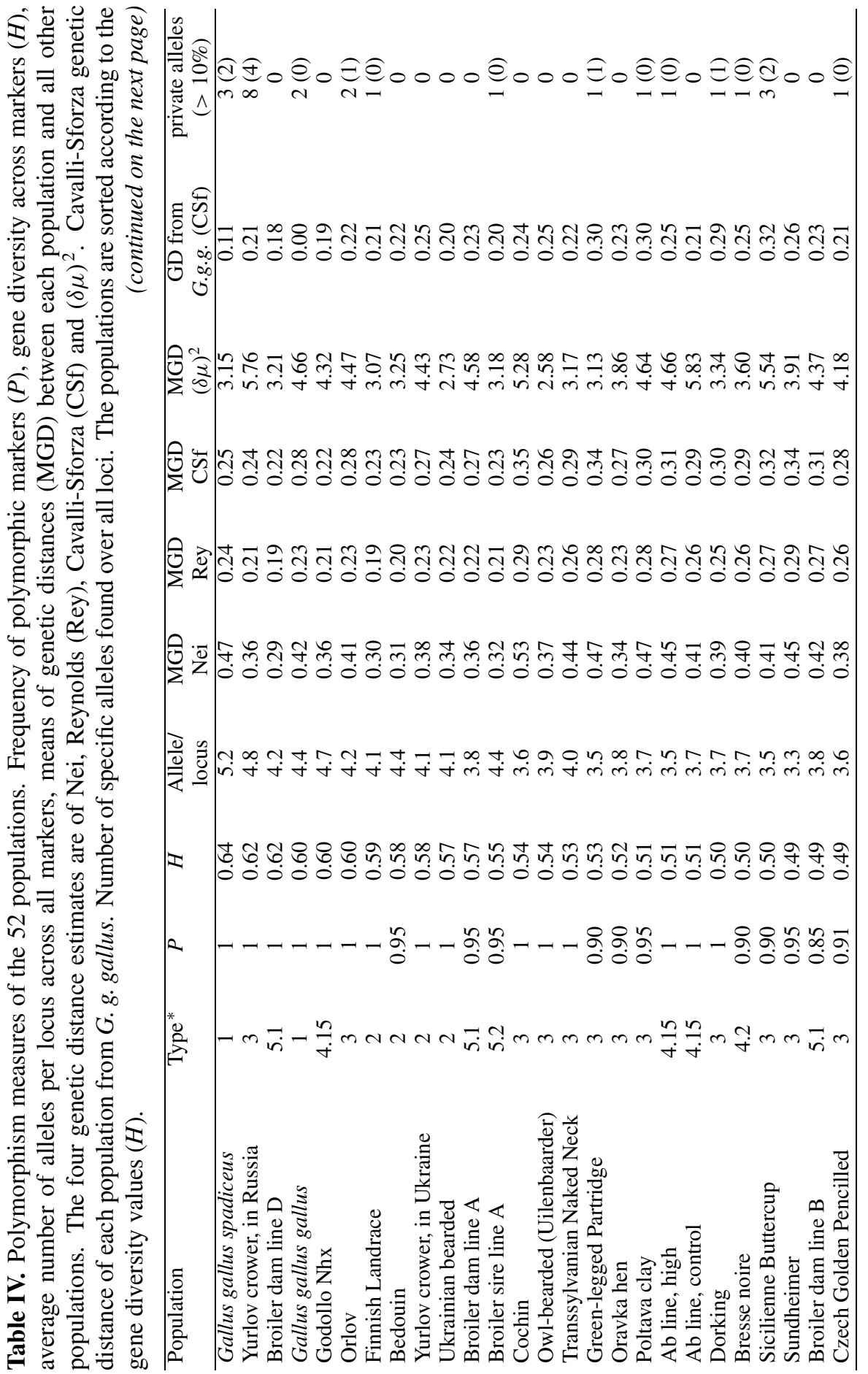




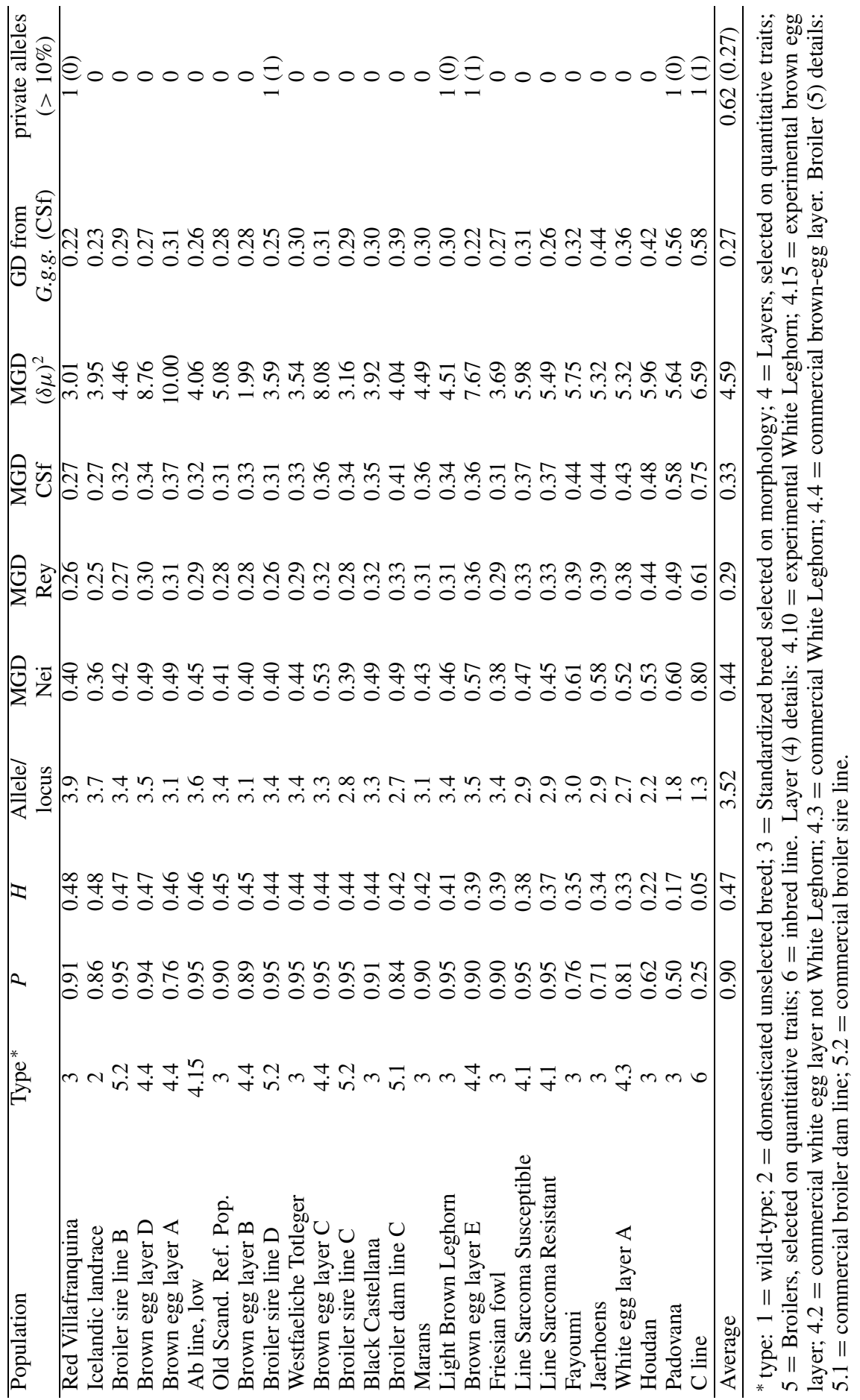


In Table IV, the 52 populations are ordered according to decreasing average gene diversity $(H)$ values across the 22 loci. To examine the stability of the $H$ values, an average $H$ over 22 possible subsets of markers, each eliminating one different marker, was calculated for each population. The average $H$, based on the 22 subsets, gave identical order of populations to the original $H$.

\subsection{Population-specific (private) alleles}

In total, 213 different alleles were scored across the 52 populations and the 22 marker loci. Most of these alleles (181) were found in more than one population. For the 52 populations, the 32 private alleles are indicated in Table IV. The majority of the populations had either no private alleles (33 populations) or a single one (14 populations) and only one population, the Yurlov crower (in Russia) had eight private alleles. The RJF subspecies: Gallus gallus gallus and Gallus gallus spadiceus with two and three private alleles respectively are worth mentioning. Taken together, the 50 domesticated populations had 91 alleles which are missing in the two RJF populations. In turn, RJF had eight private alleles which were absent in the domesticated gene pool. Among the 32 private alleles, only 14 had frequencies higher than $10 \%$.

\subsection{Mean genetic distances of the 52 populations}

Four estimates of genetic distance were calculated between each pair of populations (1326 pairwise distances for each of the four estimates). These are presented in the Poultry Biodiversity database.

For each of the 52 populations and separately for the four different estimates, we calculated the mean genetic distance (MGD) between a given population and all other 51 populations (Tab. IV). MGD shows a clear tendency to increase as polymorphism decreases. This tendency is typical of the MGD estimates based on gene frequencies [all except $\left.(\delta \mu)^{2}\right]$. For instance, Reynolds MGD values ranged between 0.19 for the Broiler dam line D and Finnish Landrace, to 0.61 for the inbred $\mathrm{C}$ line. Other MGD had different values according to the distance used. Figure 1 presents the detailed association between average number of alleles and MGD based on Cavalli-Sforza's distance.

\subsection{Diversity between and within types of populations}

Examination of Table $\mathrm{V}$ reveals the following: types 1 (wild type) and 2 (unselected breeds) were the most polymorphic populations $(H=0.62$ and 0.56 , and number of alleles per locus, $n_{a}$, are 4.8 and 4.1 respectively). Type 6 (inbred) was the least polymorphic $\left(H=0.05\right.$ and $\left.n_{a}=1.3\right)$. On average, layers (type $4 ; H=0.45$ and $n_{a}=3.4$ ) were slightly less polymorphic than broilers (type 5; $H=0.57$ and $n_{a}=3.6$ ). Among layers, Brown-egg 


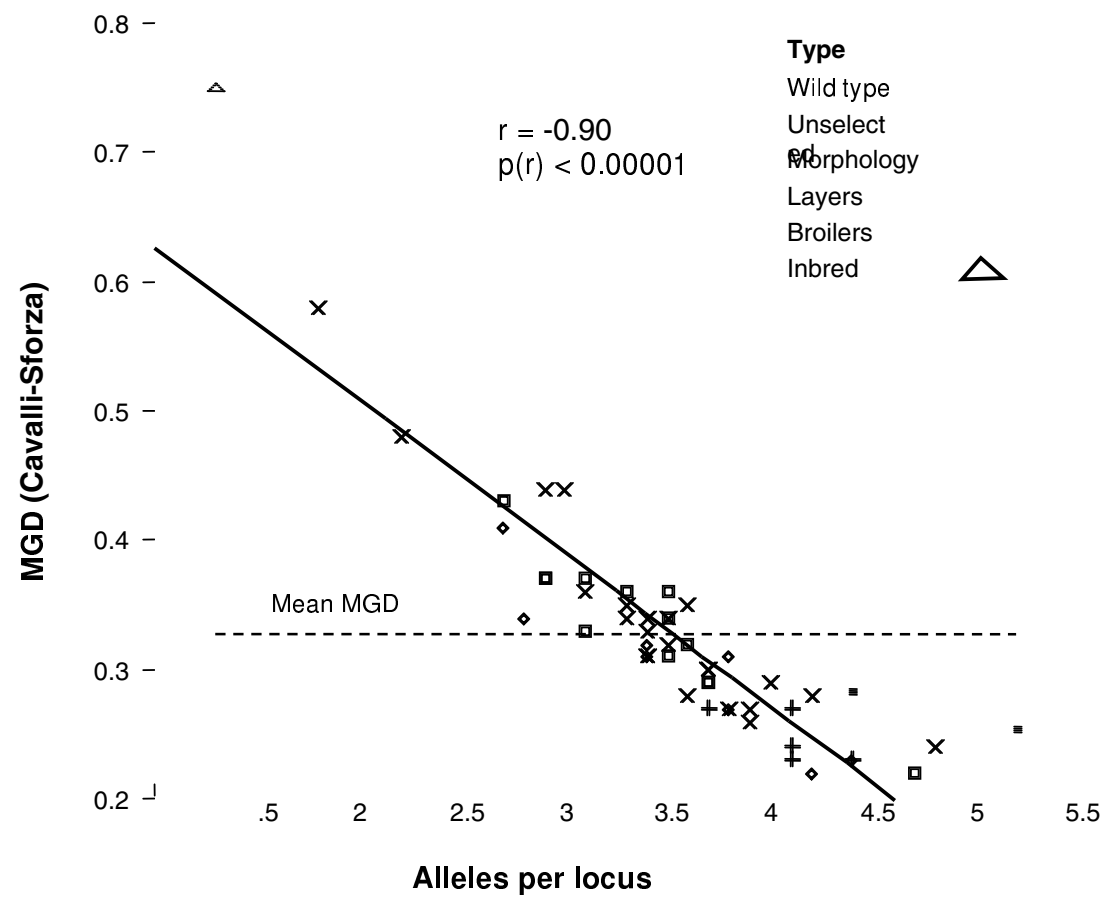

Figure 1. Association between the average number of alleles for each of the 52 populations and their mean genetic distance (MGD) from the remaining populations, based on the Cavalli-Sforza distance. The points are marked according to their chicken types.

layers were the most polymorphic, while White Leghorn breeds (sub-types 4.3 and 4.10) were less polymorphic than non-Leghorn white-egg layer breeds. Among broilers, negligible differences were found between the four dam-lines (sub-type 5.1) and the four sire-lines (sub-type 5.2). Populations of type 3 (standardized breeds, selected on morphology), had extremely different levels of polymorphism (Tab. IV and Fig. 1) ranging from the most polymorphic such as Yurlov Crower from Russia and Orlov, to the least polymorphic (except for the inbred $\mathrm{C}$ line) such as Houdan and Padovana.

In Table $\mathrm{V}$ polymorphism measures $(H, P$ and number of alleles) are given for the types and sub-types. Similarly, mean genetic distance (MGD) values are given, as well as the distance computed relative to the MGD values of G. g. gallus. It is worth noting that there is a negative association between polymorphism measures and the relative MGD values (compared to RJF) shown in parentheses. For instance, the Reynolds MGD value of the inbred C line was $260 \%$ relative to that of the G. g. gallus populations while the five polymorphic unselected populations were even lower than that of the G. g. gallus (93\%). 


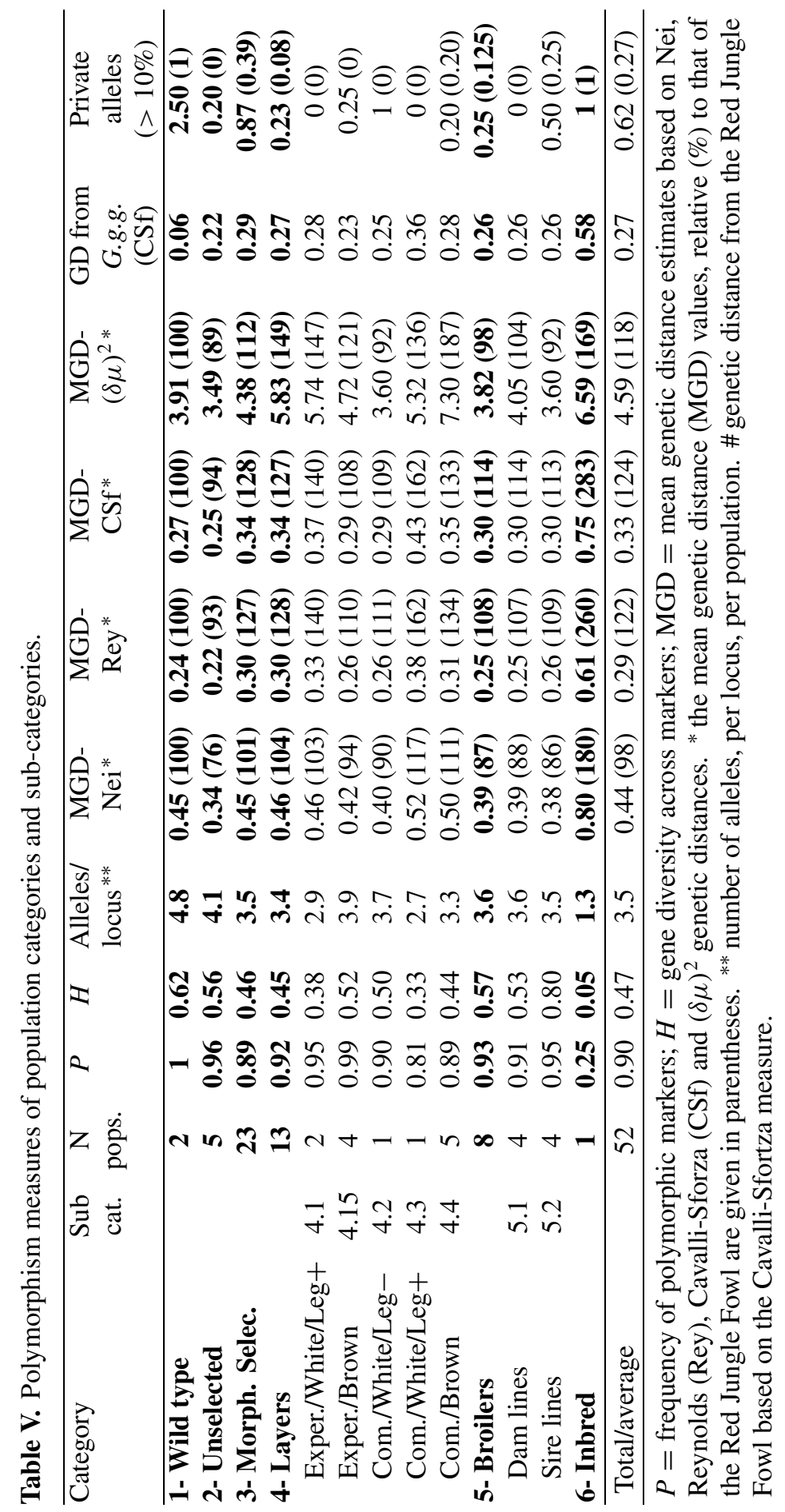


Table VI. Correlation coefficients between measurements of Table IV.

\begin{tabular}{|c|c|c|c|c|c|c|c|}
\hline & \multicolumn{3}{|c|}{ MGD } & \multicolumn{3}{|c|}{ Polymorphism } \\
\hline & & Reynolds & Cavalli & $(\delta \mu)^{2}$ & $P$ & $H$ & Alleles/locus \\
\hline \multirow[t]{8}{*}{ MGD } & Nei & 0.92 & 0.90 & 0.56 & -0.74 & -0.78 & -0.71 \\
\hline & & $* * * *$ & $* * * *$ & $* * * *$ & $* * * *$ & $* * * *$ & $* * * *$ \\
\hline & Reynolds & & 0.98 & 0.47 & -0.89 & -0.95 & -0.88 \\
\hline & & & $* * * *$ & 0.0004 & $* * * *$ & $* * * *$ & $* * * *$ \\
\hline & Cavalli & & & 0.45 & -0.90 & -0.93 & -0.90 \\
\hline & & & & 0.0008 & $* * * *$ & $* * * *$ & $* * * *$ \\
\hline & $(\delta \mu)^{2}$ & & & & -0.36 & -0.38 & -0.36 \\
\hline & & & & & 0.009 & 0.004 & 0.008 \\
\hline \multirow[t]{4}{*}{ Polym. } & $P$ & & & & & 0.86 & 0.78 \\
\hline & & & & & & $* * * *$ & $* * * *$ \\
\hline & $H$ & & & & & & 0.93 \\
\hline & & & & & & & $* * * *$ \\
\hline
\end{tabular}

\subsection{Associations between polymorphism measurements of populations}

Correlations between seven of the measurements in Table IV are recorded in Table VI. Polymorphism estimates were significantly and negatively associated with the three MGD values that are based on gene frequencies (see also Fig. 1). MGD based on the $(\delta \mu)^{2}$ approach was poorly associated with polymorphism. The correlation coefficients between MGD values and gene diversity were slightly higher than those with the proportion of polymorphic markers $(P)$. The highest association was between gene diversity and MGD values obtained from Reynolds estimates; $r=-0.95$. The associations between the different MGD measures were positive and highly significant, except for that based on $(\delta \mu)^{2}$.

\subsection{Mutation rate of microsatellites}

From the DNA pool of the RSV resistant line 3401, we scored 14 private alleles that were absent in the RSV susceptible line 3402 and for the susceptible line we scored 14 such alleles. The total number of gametes involved was 11000 (440 gametes $\times 25$ generations). The mutation rate per microsatellite per locus per generation was: $28 /(11000$ gametes $\times 22$ loci $)=1.16 \times 10^{-4}$. 


\section{DISCUSSION}

\subsection{Data reliability}

In general, the results reported here were in good agreement with what is known of the history of the populations and with previous scientific reports. For instance, the feral populations and the domesticated unselected populations were the most polymorphic, while the inbred and the White Leghorn lines were far less polymorphic. This suggests that use of DNA pools, the chosen markers and the biometrical tools described in this report, provide reliable estimates for the population's biodiversity (see also [10,12,13,24,25,31]). Furthermore, polymorphism estimates obtained from these DNA pools were found to be in good agreement with those obtained from individually typing a subset of 30 birds from 20 populations (unpublished data). For instance, the correlation coefficient between $H$ values of the current study and observed heterozygote frequency is $r=0.85(p=0.002)$ and between the number of alleles per locus is $r=0.91(p=0.0002)$. Data reliability was also supported by the same order of population $H$ values, based on 22 subsets, with single markers systematically excluded.

\subsection{Diversity of microsatellites and its mutation rate}

The wide range of biodiversity in the sampled populations and the high level of polymorphism of microsatellites were reflected by the finding that even the least polymorphic locus, MCW98 was found to be polymorphic in $69 \%$ of the populations while four of the 22 markers were polymorphic in all 52 populations (Tab. II).

The correlation coefficients between some of the polymorphism measures are high and very significant $(r=0.81-0.91$, see the diagonal of Tab. III). On the contrary, allele-size range had lower correlation coefficients with the number of alleles per population $\left(n_{a}\right)(r=0.51, p<0.01)$ and with the expected heterozygote frequency $H(r=0.41, p>0.05)$. On closer examination, for three loci, namely LEI92, MCW284 and MCW330, size ranges are larger than expected, based on their $n_{a}$ and $H$ values. For LEI192, six of the sixteen alleles across populations were present in only a single population and two alleles in two populations. Excluding these eight alleles, reduced the range from $74 \mathrm{bp}$ to $46 \mathrm{bp}$. Similar treatment of the loci MCW284 and $M C W 330$ reduced the number of alleles across populations from eleven to two and from ten to four, respectively. Similarly, allele size ranges reduced from $46 \mathrm{bp}$ to $8 \mathrm{bp}$ for $M C W 284$ and from $39 \mathrm{bp}$ to 30 for MCW330. These can be interpreted either as population-specific (private) alleles or as signal peaks in the sequencer machine that are not alleles. Discrimination between these is 
possible only by analyzing sibships, which is out of the scope of the present report.

In studies of human genetic variation, at the continental level there is good agreement in the ordering by region of gene diversity measures among different kinds of markers, once ascertainment bias is removed [29,39]. The same is true for the ordering of genetic distances among populations assessed for different markers [29]. It is reasonable therefore to believe, that the ordering among chicken breeds of diversity and distances seen here for microsatellites in DNA pools would not be very different for other genetic marker systems. The microsatellite loci used here were selected to be polymorphic for use in gene mapping. However, Rosenberg et al. [42] obtained diversity and genetic distance patterns for humans that largely agreed with those of Bowcock et al. [2] even though the former study used microsatellites from a mapping set and the latter used markers that were not selected. Ascertainment bias is, therefore, not expected to have had a major effect on the ordering of statistics for our chicken data.

The estimation of the mutation rate using the divergently selected (RSV) lines is based on the assumption that the 22 microsatellite markers are not linked to genes that are affected by the selection criteria. Weber and Wong found a mutation rate of $5.6 \times 10^{-4}$ for di-nucleotide loci in humans by pedigree analysis [46]. Based on 22 di-nucleotide loci, our estimate was about five times lower, but may underestimate the actual value since it was assumed that no reverse or recurrent mutations occurred. Since this estimate is from a single set of divergently selected lines, we cannot estimate confidence limits of this rate. Further analysis of chickens is needed to provide a reliable estimate of mutation rate.

\subsection{Genetic diversity of populations}

A gene diversity of 0.48 was obtained from DNA pools in a subset of 20 populations. Based on individual typing of the same subset, the frequency of heterozygotes was 0.47 (unpublished data). These estimates are similar to the average $H$ in all 52 populations indicating the good reliability of our estimates. Diversity estimates in this study are lower than the observed frequencies of heterozygotes reported in other species using microsatellite markers. For instance, in human populations the average heterozygote frequency ranges between 0.7 and 0.8 [2], in cattle- 0.6 [11], in pigs- 0.68 [21] and in fish0.86 [16]. Although such comparisons are difficult to interpret, the lower variability in chickens calls attention to the importance of conserving the chicken gene pool. It is worth mentioning, however, that SNP frequency in the chicken genome was found to be quite high and significantly higher than that found in the human genome (unpublished data). 


\subsection{Diversity between populations within types}

Categorization of populations in this study was done according to the populations' history and their breeding purpose, which have affected the genetic diversity. Indigenous stocks are domesticated but unselected local breeds (type 2) that have persisted in the agricultural societies for decades or even centuries. Their long history in certain regions might have led to specific adaptation to local environmental conditions and genetic changes due to natural selection and to some degree due to genetic drift as well. In practice, four out of the five populations of type 2 had relatively high polymorphism, which may reflect their rather large effective population size and the fact that these stocks were not subjected to intense selection for production.

The group of standardized breeds (type 3) selected for morphological traits covers a wide range of various breeds kept by fanciers. This type has large variance in polymorphism levels (Tab. IV) as also reflected in the scattered pattern of its populations in Figure 1. Based on genetically distinct local populations, pure breeds were developed that differed in many phenotypic traits such as plumage color, plumage pattern, and comb type. Genetic changes in fancy breeds may occur rather rapidly in these relatively small populations because of intense selection for exhibition traits, inbreeding, crossbreeding genetic drift, bottleneck and founder effects $[17,35,36]$. This complexity of histories and breeding practices may explain the heterogeneity of polymorphism values that characterizes type 3 .

Types 4 (layers) and 5 (broilers) of chicken lines, which are selected for quantitative traits, encompass the major commercial poultry industry. Estimates for broilers $(H=0.57)$ were in agreement with a previous report, in which $H=0.53$ was obtained from pooled blood samples [10]. The White Leghorn layer line in our study (sub-type 4.3) was found to have low gene diversity (0.33), slightly higher than the value of 0.27 in the previous report [10]. Among the layers this line had the lowest polymorphism.

In the 1940s, poultry breeding began to develop as a business. Pure bred lines were used to develop specialized commercial breeding stocks for table egg and meat production by applying highly efficient and intense breeding programs. Industrial egg and meat stocks are bred by large multinational breeding companies, and the "end products" are hybrids based mostly on four highly selected grandparental lines. In particular during the last decades efforts have been made to limit inbreeding in these grandparental pure bred lines [37]. Large flock sizes and limiting inbreeding may be reflected by the degree of polymorphism of these types (4 and 5) which is comparable even to those of populations that were not subjected to intensive breeding. It should be noted here that the commercial lines in our study are all pure bred lines. Therefore, their level of polymorphism can be considered as a reliable estimate for the polymorphism of the pure-bred grandparental lines. Differences within 
types 4 and 5 might be explained by the different origin of white egg layers, brown egg layers and broilers. White egg layers are chiefly represented by one breed, the Single Comb White Leghorn breed, while the genetic basis for brown egg layers has been somewhat broader, mainly coming from the Rhode Island Red, New Hampshire, Plymouth Rock and Australorp breeds. A similar picture is characteristic of the poultry meat production sector. The paternal grandparent lines are mainly derived from the White Cornish breed, while maternal grandparents are heavily based on White Plymouth Rocks. The Cornish was developed in England from Asiatic fighting stocks, and the White Plymouth Rock was derived from an American parent breed [6].

The low degree of gene diversity in the inbred $\mathrm{C}$ line resulted directly from the brother-sister mating scheme used to develop this line and possibly from genetic drift due to the limited effective population size.

\subsection{Genetic distance measures}

The three genetic distance measures which are based on gene frequencies were in good agreement with the genetic diversity of the examined breeds, indicating that these approaches fit the history of the domesticated chickens well. However, the $(\delta \mu)^{2}$ approach that is based on the allele size which is typical to microsatellites, was different and poorly correlated with other genetic distances as well as measures of diversity. Probably the history of the domesticated chicken does not meet the assumptions behind this approach especially the constant population size.

\subsection{Conceptual aspects of MGD}

A domesticated population with a large number of alleles per locus is expected to represent a large portion of the studied gene pool and therefore to be genetically close to all other populations. Populations of types 1 and 2 are polymorphic and represent the gene pool well and indeed have low values of MGD. On the contrary, populations that are relatively monomorphic cannot reflect the whole studied gene pool and therefore will have high MGD values, as evidenced by the inbred $\mathrm{C}$ line and a few populations from types 3 and 4.3. Figure 1 shows a negative and clear association between the average number of alleles per locus and the Cavalli-Sforza MGD values. A similar and tighter association is apparent when gene diversity values are examined. The clear association discussed above between polymorphism and MGD values suggests that the approach of constructing evolutionary trees in domesticated populations is likely to give a misleading picture of the history. This is particularly true for rooted trees, which assume a unidirectional evolutionary process. It seems that the processes of domestication and breeding have involved more or less continuous and multidirectional gene flow. 
Careful examination of Figure 1 reveals that populations with a similar number of alleles may have different MGD values. The joint distribution of the number of alleles and MGD values can be viewed with a regression line that will be termed a "trend line", as in Figure 1. The unselected populations (type 2) are highly polymorphic and located next to or below the trend line, implying that many of their alleles are common to the studied gene pool. The two Gallus gallus subspecies have a large number of alleles per locus but are both located above the trend line, which implies some proportion of private alleles. Indeed, five private alleles that are absent in the domesticated chicken were found to be present in G. g. gallus and six such alleles in G. g. spadiceus.

\subsection{The chicken ancestor and the need for conservation}

It is assumed that all breeds of the domesticated chicken descend from a single ancestor, the RJF, which originated in Southeast Asia $[5,14,15]$. Since populations at the centre of origin should contain the highest diversity (as has been shown for humans and other species [2]), RJF should present a high level of polymorphism and also hold low values of MGD. The two sub-species of Gallus gallus (RJF) which are represented in this study have high diversity values and low MGD values, but not the lowest (Tab. IV and Fig. 1). These results suggest the hypothesis that the Red Jungle Fowl is a major contributor to the gene pool of the domesticated chicken. The presence of private alleles both in the RJF and in the domesticated gene pool does not necessarily contradict this hypothesis. These private alleles could result from genetic drift and separate evolution since the onset of domestication. Additionally, private alleles of the domesticated breeds may indicate a contribution of other wild species as debated in Crawford [5]. In studies on the mitochondrial DNA in chickens [14, 15], the authors suggest that Gallus gallus gallus could have given rise to the diverse breeds of the domesticated chicken, even though common patterns in domesticated breeds and in G. g. spadiceus and G. g. bankiva are also observed.

With regards to the level of genetic polymorphism and the mean genetic distance, the Red Jungle Fowl (Gallus gallus) appears to be an important reservoir of the chicken polymorphism. Nevertheless, during domestication, extensive genetic diversity has accumulated in the chicken, and this diversity is displayed by the many breeds and strains differing in their phenotypes which are the products of many genetic, environmental and management regimes. A complete description of each breed or population would entail ascertaining all genes that contribute to any phenotypic trait. It is very unlikely that such complete knowledge can be achieved in the near future. Therefore, a more practical alternative is needed. We believe that information from DNA markers together with phenotypic performance and population history may provide reliable guidelines in choosing populations for practical and for conservation purposes. However, setting conservation priorities based exclusively on the 
diversity of molecular markers might lead to the loss of locally adapted populations [32].

In recent years, breeders of commercial white-egg layers have been concerned about reduced genetic variability and future response to selection. The results reported in the present article support this concern, particularly for White Leghorn breeds. The massive merging of breeding companies in recent years should call for attention to the need for conservation of genetic variation among breeds and lines. Appropriate strategies for conservation of populations is out of the scope of the present report but is an important and controversial issue [7]. Our results emphasize the need to conserve polymorphic populations such as Yurlov Crower, the Orlov or the Finnish Landrace for the sake of global variability, and to preserve small populations for their unique genetic features. MGD values can assist in choosing populations most valuable for the preservation of genetic variation.

\section{ACKNOWLEDGEMENTS}

We wish to thank Jean-Luc Coville and Camilo Vilela-Lamego, Inra, Jouyen-Josas, France, who were involved in the DNA preparation and its distribution, and to the following sub-contractors who provided the blood samples and breed descriptions; without their help this study could not have been performed (they are listed alphabetically): Dr. G. Baldane, Padova, Italy; Dr. J. Baumgartner, Research Institute, Ivanka pri Dunaji, Slovakia; Dr. Y. Bondarenko, Research Institute; Borky, Kharkiv, Alaska; Dr. J.L. Campo, INIA, Madrid, Spain; D. Cassuto, ANAK, Israel; Dr. K. Cywa-Benko, Research Institute, Balice n Cracow, Poland; Dr. E. Eythorsdottir, RALA, Israel; Y. Jego, Hubbard-ISA, France; Dr. J. Kathle, NLH, Norway; Dr. I. Moiseyeva, Research Institute, Gubkin, Moscow, Russia; Dr. G. Pidone, Calatafimi, Italy; Prof. R. Preisinger Lohmann, Germany; M. Protais, Hubbard-ISA, France; P. Rault, SYSAAF, Tours, France; Mrs. V. Roberts, UK; Dr. P. Sorensen, DIAS, Denmark; Dr. I. Szalay, Hungary; Prof. Therdchai Vearasilp, Thailand; Dr. B. Thorp Ross Breeders, Aviagene, UK; Dr. P. Trefil, Biopharmacy Institute, Prague, Czech Republic; F. van Sambeek, Hendrix, Ospel, The Netherlands; Dr.Vilhelmova, Czech Republic; J. Vincent, Cobb, UK; Dr. G. Virag, Research Institute, Godollo, Hungary.

\section{REFERENCES}

[1] Barker J.S.F., Bradley D.G., Fries R., Hill W.G., Nei M., Wayne R.K., An integrated global protocol to establish the genetic relationships among the breeds of each domestic animal species, Report of a Working Group, Animal Production and Health Division, FAO, 1993. 
[2] Bowcock A.M., Ruiz-Linares A., Tomfohrde J., Minch E., Kidd J.R., CavalliSforza L.L., High-resolution of human evolutionary trees with polymorphic microsatellites, Nature 368 (1994) 455-457.

[3] Cavalli-Sforza L.L., Edwards K.J., Phylogenetic analysis: models and estimation procedures, Am. J. Hum. Genet. 19 (1967) 233-257.

[4] Cheng H.H., Crittenden L.B., Microsatellite markers for genetic mapping in the chicken, Poult. Sci. 73 (1994) 539-546.

[5] Crawford R.D., Domestic fowl, in: Mason I.L. (Ed.), Evolution of domesticated animals, Longman, London, 1984, pp. 298-311.

[6] Crawford R.D., Origin and history of poultry species, in: Crawford R.D. (Ed.), Poultry Breeding and Genetics, Elsevier, New York, 1990, pp. 317-329.

[7] Crawford R.D., Christman C.J., Heritage Hatchery Networks in Poultry Conservation, in: Alderson L., Bodo I. (Eds.), Genetic Conservation of Domestic Livestock, CAB International, Oxon, UK, 1992, pp. 121-122.

[8] Crooijmans R.P.M.A., Van Kampen A.J.A., Van der Poel J.J., Groenen M.A.M., Highly polymorphic microsatellite markers in poultry, Anim. Genet. 24 (1993) 441-443.

[9] Crooijmans R.P.M.A., Van Oers P.A.M., Strijk J.A., Van der Poel J.J., Groenen M.A.M., Preliminary linkage map of the chicken (Gallus domesticus) genome based on microsatellite markers: 77 new markers mapped, Poult. Sci. 75 (1996) $746-754$.

[10] Crooijmans R.P.M.A., Groen A.F., Van Kampen A.J.A., Van der Beek S., Van der Poel J.J., Groenen M.A.M., Microsatellite polymorphism in commercial broiler and layer lines estimated using pooled blood samples, Poult. Sci. 75 (1996) 904-909.

[11] de Gortari M.J., Freking B.A., Kappes S.M., Leymaster K.A., Crawford A.M., Stone R.T., Beattie C.W., Extensive genomic conservation of cattle microsatellite heterozygosity in sheep, Anim. Genet. 28 (1997) 274-290.

[12] Dunnington E.A., Gal O., Plotsky Y., Haberfeld A., Kirk T., Goldberg A., Lavi U., Cahaner A., Siegel P.B., Hillel J., DNA fingerprints of chickens selected for high and low body weight for 31 generations, Anim. Genet. 21(1990) 221-231.

[13] Dunnington E.A., Stallard L.C., Hillel J., Siegel P.B., Genetic diversity among commercial chicken populations estimated from DNA fingerprints, Poult. Sci. 73 (1994) 1218-1225.

[14] Fumihito A., Miyake T., Sumi S., Takada M., Ohno S., Kondo N., One subspecies of the red jungle fowl (Gallus gallus gallus) suffices as the matriarchic ancestor of all domestic breeds, Proc. Natl. Acad. Sci. USA. 91 (1994) 12505-12509.

[15] Fumihito A., Miyake T., Takada M., Shingu R., Endo T., Gojobori T., Kondo N., Ohno S., Monophyletic origin and unique dispersal patterns of domestic fowls, Proc. Natl. Acad. Sci. USA 93 (1996) 6792-6795.

[16] Garcia de Leon F.J., Dallas J.F., Chatain B., Canonne M., Versini J.J., Bonhomme F., Development and use of microsatellite markers in sea bass, Dicentrarchus labrax (Linnaeus, 1758) (Perciformes: Serrandidae), Mol. Mar. Biol. Biotechnol. 4 (1995) 62-68.

[17] Gill J.J.B., Kelly E.P., Genetic variation in rare breeds and the measurement of homozygosity, in: Alderson L., Bodo I. (Eds.), Genetic Conservation of Domestic Livestock, CAB International, Oxon, UK, 1990, pp. 175-185. 
[18] Goldstein D.B., Linares A.R., Cavalli-Sforza L.L., Feldman M.W., An evaluation of genetic distances for use with microsatellite loci, Genetics 139 (1995) 463471.

[19] Goldstein D.B., Linares A.R., Cavalli-Sforza L.L., Feldman M.W., Genetic absolute dating based on microsatellites and the origin of modern humans, Proc. Natl. Acad. Sci. USA 92 (1995) 6723-6727.

[20] Groen A.F., Crooijmans R.P.M.A., Van Kampen A.J.A., Van der Beek S., Van der Poel J.J., Groenen M.A.M., Microsatellite polymorphism in commercial broiler and layer lines, in: Proceedings of the 5th World Congress on Genetics Applied to Livestock Production, Guelph, 7-12 August, 1994, Vol. 21, University of Guelph, Ontario, pp. 94-97.

[21] Groenen M.A., Ruyter D., Verstege E.J., de Vries M., Van der Poel J.J., Development and mapping of ten porcine microsatellite markers, Anim. Genet. 26 (1995) $115-118$.

[22] Groenen M.A.M., Cheng H.H., Bumstead N., Benkel B., Briles E., Burt D.W., Burke T., Dodgson J., Hillel J., Lamont S., Ponce de Leon F.A., Smith G., Soller M., Takahashi H., Vignal A., Consensus linkage map of the chicken genome, Genome Res. 10 (2000) 137-147.

[23] Hartmann W., von dem Hagen D., Selektion von Leghornlinien auf Resistenz gegen Infektion durch Leukoseviren, Monatshefte Veterinärmedizin 39 (1984) 86-89.

[24] Hillel J., Plotzky Y., Gal O., Haberfeld A., Lavi U., Dunnington E.A., Siegel P.B., Jeffreys A.J., Cahaner A., DNA fingerprint in chickens, in: Proceedings of the 31st British poultry breeders roundtable, 20-22 September 1989, Reading.

[25] Hillel J., Avner R., Baxter-Jones C., Dunnington E.A., Cahaner A., Siegel P.B., DNA fingerprints from blood mixes in chickens and turkeys, Anim. Biotechnol. 2 (1990) 201-204.

[26] Hillel J., Korol A., Kirzner V., Freidlin P., Weigend S., Barre-Dirie A., Groenen M.A.M., Crooijmans R.P.M.A., Tixier-Boichard M., Vignal A., Wimmers K., Burke T., Thomson P.A., Maki-Tanila A., Elo K., Zhivotovsky L.A., Feldman M.W., Biodiversity of Chickens based on DNA pools: first results of the EC funded project AVIANDIV, in: Proceedings of the Poultry Genetic Symposium, 6-8 October 1999, Mariensee, Germany, pp. 22-29.

[27] Hunton P., Industrial breeding and selection, in: Crawford R.D. (Ed.), Poultry Breeding and Genetics, Elsevier, New York, 1990, pp. 1-42.

[28] JMP ${ }^{\circledR}$, Statistical discovery software (version 4.0). SAS ${ }^{\circledR}$ Institute Inc. NC, USA.

[29] Jorde L.B., Watkins W.S., Bamshad M.J., Dixon M.E., Ricker C.E., Seielstad M.T., Batzer M.A., The distribution of human genetic diversity: A comparison of mitochondrial, autosomal, and Y-chromosome data, Am. J. Hum. Genet. 66 (2000) 979-988.

[30] Kavaca M., Karaca F.G., Patel C., Emara M.G., Preliminary analysis of microsatellite loci in commercial broiler chickens, in: Plant and Animal Genome VII Conference, 17-21 January, San Diego, 1999, CA, USA.

[31] Khatib H., Darvasi A., Plotski Y., Soller M., Determining relative microsatellite allele frequencies in pooled DNA samples, PCR Methods and Applications 4 (1994) 13-18. 
[32] McKay J.K., Bishop J.G., Lin J., Richards J.H., Sala A., Mitchell-Olds T., Local adaptation across a climatic gradient despite small effective population size in the rare sapphire rockcress, Proc. R. Soc. Lond. B Biol. Sci. 268 (2001) 1715-1721.

[33] Moiseyeva I.G., Yuguo Z., Nikiforov A.A., Zakharov I.A., Comparative analysis of morphological traits in mediterranean and chinese chicken breeds: the problem of the origin of the domestic chicken, Russian J. Genet. 32 (1996) 1553-1561.

[34] Nei M., Genetic distance between populations, Am. Nat. 106 (1972) 283-292.

[35] Obata T., Takeda H., Oishi T., Japanese native livestock breeds, Anim. Genet. Resour. Inf. (UNEP-FAO) 13 (1994) 13-24.

[36] Ponsuksili S., Wimmers K., Schmoll F., Horst P., Schellander K., Comparison of multilocus DNA fingerprints and microsatellites in an estimate of genetic distance in chicken, J. Hered. 90 (1999) 656-659.

[37] Preisinger R., Zuchtstrategien für eine nachhaltige Legehennenzucht, Lohmann Inf. 2 (2000) 3-6.

[38] Reynolds J., Weir B.S., Cockerham C.C., Estimation of the co-ancestry coefficient basis for a short-term genetic-distance, Genetics 105 (1983) 767-779.

[39] Rogers A.R., Jorde L.B., Ascertainment bias in estimates of average heterozygosity, Am. J. Hum. Genet. 58 (1996) 1033-1041.

[40] Romanov M.N., Weigend S., Analysis of genetic relationships between various populations of domestic and jungle fowl using microsatellite markers, Poult. Sci. 80 (2001) 1057-1063.

[41] Rosenberg N.A., Burke T., Feldman M.W., Freidlin P.J., Groenen A.M., Hillel J., Mäki-Tanila A., Tixier-Boichard M., Vignal A., Wimmers K., Weigend S., Empirical evaluation of genetic clustering methods using multilocus genotypes from twenty chicken breeds, Genetics 159 (2001) 699-713.

[42] Rosenberg N.A., Pritchard J.K., Cann H., Weber J., Kidd K.K., Zhivotovsky L.A., Feldman M.W., Genetic structure of human populations, Science 298 (2002) 2381-2385.

[43] Teale A.J., Tan S.G., Tan J.H., Applications of molecular genetic and reproductive technologies in the conservation of domestic animal diversity, in: Proceedings of the 5th World Congress on Genetics Applied to Livestock Production, Guelph, 7-12 August 1994, Vol. 21, University of Guelph, Ontario, pp. 493-500.

[44] Tixier-Boichard M., Coquerelle G., Vilela-Lamego C., Weigend S., Barre-Dirrie A., Groenen M., Crooijmans R., Vignal A., Hillel J., Freidlin P., Wimmers K., Ponsuksili S., Burke T., Thomson P., Elo K., Maki-Tanila A., Baldane G., Baumgartner J., Benkova J., Bondarenko Y., Podstreshny A., Campo J., CywaBenko K., Jego Y., Knizetova H., Moiseeva I., Protais M., Pidone G., Rault P., Trefil P., van Sambeek F., Virag G., Hidas A., Contribution of data on history, management and phenotype to the description of the diversity between chicken populations sampled within the AVIANDIV project, in: Proceedings of the Poultry Genetic Symposium, 6-8 October 1999, Mariensee, Germany, pp. 15-21.

[45] Vanhala T., Tuiskula-Haavisto M., Elo K., Vilkki J., Maki-Tanila A.S.O., Evaluation of genetic variability and genetic distances between eight chicken lines using microsatellite markers, Poult. Sci. 77 (1998) 783-790.

[46] Weber J.L., Wong C., Mutation of human short tandem repeats, Hum. Mol. Genet. 2 (1993) 1123-1128. 
[47] Weigend S., Assessment of Biodiversity in poultry with DNA markers, in: Proceedings of the Poultry Genetic Symposium, 6-8 October 1999, Mariensee, Germany, pp. 7-14.

[48] Zhou H., Lamont S.J., Microsatellite markers to estimate genetic differences among pedigree-defined inbred chicken lines of commercial and exotic origin, in: Proceedings "From Jay Lush to Genomics": Visions for Animal Breeding and Genetics, 1999, Iowa, USA, p. 175 (abstract).

To access this journal online: www.edpsciences.org 